\title{
PRODUÇÃO DE FITOMASSA DE DIFERENTES ESPÉCIES DE COBERTURA E SUAS ALTERAÇÕES NA ATIVIDADE MICROBIANA DE SOLO DE CERRADO $\left({ }^{1}\right)$
}

\author{
MARCO AURÉLIO CARBONE CARNEIRO $\left({ }^{2 *}\right)$; MEIRE APARECIDA SILVESTRINI CORDEIRO $\left({ }^{3}\right)$; \\ PAULA CAMYLLA RAMOS ASSIS $\left({ }^{2}\right)$; ELSON SILVA MORAES $\left({ }^{2}\right)$; HAMILTON SERON PEREIRA $\left({ }^{2}\right)$; \\ HELDER BARBOSA PAULINO $\left({ }^{2}\right)$; EDICARLOS DAMACENA DE SOUZA $\left({ }^{2}\right)$
}

\begin{abstract}
RESUMO
O objetivo deste estudo foi avaliar a produção de fitomassa de nove espécies de cobertura do solo e verificar as alterações na atividade e biomassa microbiana de solo de cerrado. O trabalho foi desenvolvido de março a dezembro de 2004, em Latossolo Vermelho distroférrico, sendo semeadas as seguintes espécies de cobertura: aveia-preta (Avena strigosa), guandu (Cajanus cajan), Crotalaria juncea, lablabe (Lablab purpureum), milheto (Pennicetum americanum), nabo forrageiro (Raphanus sativus), níger (Guizotia abyssinica (L.F.) Cass.), feijão-de-porco (Canavalia ensiformis.) e Crotalatia spectabilis. Uma área em pousio foi considerada como referência. Na ocasião do florescimento, determinou-se a quantidade de fitomassa e, a partir de agosto, parte dela foi acondicionada em sacos de polietileno, ficando no solo por 120 dias, para se avaliar a razão de decomposição. Durante esse período, no inicio de cada mês, foram avaliados o carbono da biomassa microbiana e a respiração microbiana do solo. As espécies mais promissoras para produção de fitomassa foram o guandu, milheto, feijão-de-porco e niger. O carbono da biomassa microbiana foi negativamente afetado nas áreas com resíduos de milheto, nabo forrageiro, crotalária espectábilis e naquela em pousio. $\mathrm{Na}$ área sob pousio, verificou-se a menor produção de fitomassa, além da redução no carbono da biomassa microbiana e mais perda de carbono, sendo esta prática não indicada para a região de cerrado.
\end{abstract}

Palavras-chave: plantas de cobertura, razão de decomposição, biomassa microbiana, $q \mathrm{CO}_{2}$, quociente microbiano.

$\left({ }^{1}\right)$ Recebido para publicação em 6 de outubro de 2005 e aceito em 5 de outubro de 2007.

$\left({ }^{2}\right)$ Universidade Federal de Goiás, Campus de Jataí - Centro de Ciências Agrárias e Biológicas - Laboratório de Solos. BR 364, km 192, 75800-000 Jataí (GO). E-mail: carbonecarneiro@yahoo.com.br (*) Autor correspondente; hseron@uol.com.br; helderlino51@yahoo.com.br; paulacamylla09@bol.com.br;

$\left({ }^{3}\right)$ Universidade Federal de Lavras, Caixa Postal 03, 35200-000 Lavras (MG). E-mail: meiresilves@yahoo.com.br 


\title{
ABSTRACT \\ PHYTOMASS YIELD OF DIFFERENT COVER CROPS AND ALTERATIONS IN THE MICROBIAL ACTIVITY IN A CERRADO SOIL IN BRAZIL
}

\begin{abstract}
The objective of this study was to evaluate the phytomass yield of nine species of cover crops of the soil and to verify the alterations in the activity and microbial biomass of Cerrado soil, in the State of Goiás, Brazil. The work was developed from March to December, 2004, being sowed the following covering species: Avena strigosa, Cajanus cajan, Crotalaria juncea, Lablab purpureum, Pennicetum americanum, Raphanus sativus, Guizotia abyssinica, Canavalia ensiformis, Crotalatia spectabilis and an area in fallow considered with reference. In the occasion of the flower phytomass yield was determined and starting from August it leaves of this was conditioned in sacks of polyethylene to evaluate the decomposition tax, being in the soil for 120 days. During this period, in every month, they were evaluating the carbon of the microbial biomass and the microbial respiration of the soil. The Cajanus cajan, Pennicetum americanum, Canavalia ensiformis and Guizotia abyssinica are shown as the most promising species for phytomass yield, while the Avena strigosa, Crotalaria juncea and the Raphanus sativus present the smallest phytomass yield. The areas under Pennicetum americanum residues, Raphanus sativus, Crotalatia spectabilis and the fallow affect the carbon of the microbial biomass negatively. Area under resting provided to smallest phytomass yield, reduction in the carbon of the microbial biomass and larger loss of carbon, being this practice no suitable for the Cerrado region.
\end{abstract}

Key words: cover crops, decomposition, microbial biomass, $q \mathrm{CO}_{2}$, microbial quotient

\section{INTRODUÇÃO}

A cobertura vegetal tornou-se fator de importância para a proteção do solo e à formação de palha, com redução significativa dos prejuízos e contribuição na melhoria dos atributos físicos, químicos e biológicos (BRAgAgnolo E MielniczUK, 1990). Uma adequada espécie vegetal para a cobertura do solo, principalmente na região do cerrado, deve ser de fácil estabelecimento, rápido desenvolvimento, grande agressividade para o controle de plantas infestantes, tolerante aos longos períodos de estiagem, facilidade de eliminação e não competição com a cultura subseqüente (LAL, 1979). Além desses fatores prevê-se a ciclagem de nutrientes fixados, como o nitrogênio e a mobilização e translocação daqueles na subsuperfície para a superfície do solo.

A utilização de espécies de cobertura para a formação de palha é um requisito importante para a implantação/manutenção do sistema de plantio direto. De modo geral, há falta de opção de culturas para o cerrado, com predominância do cultivo de soja no verão e do milho em sucessão, na safrinha, em locais onde há precipitação pluvial suficiente. Quando não há safrinha, o solo fica descoberto por mais tempo, sendo o milheto ou o sorgo eventualmente utilizados como culturas de cobertura nos meses antecedentes à semeadura. Nesse período, o solo fica exposto à ação direta das chuvas, causando-se, dessa forma, perdas, principalmente de água, com prejuízos aos atributos físicos, químicos e biológicos (FIALHO et al., 1991). Uma das alternativas a esse problema consiste no cultivo de espécies vegetais com possibilidade de produção de elevada fitomassa para formação de palha (Assıs et al., 2003), bem como permanência duradoura na superfície do solo. No entanto, devido às elevadas temperaturas associadas com elevada umidade do ar, é provocado aumento na razão de decomposição dos resíduos vegetais, principalmente quando se utilizam espécies com baixa relação $\mathrm{C} / \mathrm{N}$, como no caso das leguminosas, sendo prejudicada a formação de palha em quantidade necessária para implantação/manutenção do sistema de plantio direto.

O processo de decomposição é diferenciado entre leguminosas e gramíneas, sendo dependente da qualidade bromatológica das espécies vegetais, principalmente, em relação à concentração de nitrogênio, das condições climáticas e da atividade microbiana no solo. As espécies de cobertura do solo da família das fabaceaes (leguminosas) são mais utilizadas como adubos verdes devido à incorporação de nitrogênio fixado pelas bactérias fixadoras, associadas às raízes, e à rápida decomposição de sua palha, provocada pela relação $\mathrm{C} / \mathrm{N}$ inferior a 20 , sendo importante na ciclagem de nutrientes (Rosolem et al., 2003). Na família das poáceas (gramíneas), devido à elevada relação $\mathrm{C} / \mathrm{N}$, entre 30 e 40 , sua permanência no solo é maior, com contribuição para formação de palha, melhoria da estrutura do solo, principalmente da estabilização dos agregados, devido ao sistema radicular agressivo e abundante, sendo constituída também, de uma reserva de nutrientes imobilizados na palha que podem ser liberados lentamente (Pauletti, 1999). 
Outro ponto importante no processo de decomposição é a atuação dos microrganismos heterotróficos, representados pela biomassa microbiana, cuja concentração é variável de $1 \%$ a $4 \%$ da matéria orgânica do solo. É considerada a fração viva da matéria orgânica no solo, com a qual são regulados os principais processos como: o estoque e o fluxo de carbono e a ciclagem de nutrientes no solo, os quais são liberados durante a decomposição/ mineralização do material orgânico, sendo um indicador da qualidade do solo (WARDLE, 1992; Siqueira et al., 1994; Rice et al., 1996). Os efeitos das espécies de cobertura do solo na biomassa microbiana do solo são diferentes entre si (Colozzi Filho et al., 2001) e, apesar de sua importância, pouco se sabe da interferência da cobertura na atividade e biomassa microbiana do solo, principalmente em solos de cerrado.

Portanto, a determinação de espécies de cobertura do solo adaptadas para a região de cerrado, aliada ao conhecimento de sua influência na atividade microbiana do solo é de extrema importância para se propor estratégias para agroecossistemas sustentáveis naquela região.

No presente estudo, os objetivos foram os de verificar o desempenho de nove espécies vegetais na produção de fitomassa e avaliar as alterações promovidas por essas espécies na atividade e biomassa microbiana em um Latossolo Vermelho distroférrico de cerrado.

\section{MATERIAL E MÉTODOS}

O trabalho foi desenvolvido em campo experimental do Centro de Ciências Agrárias e Biológicas da Universidade Federal de Goiás, Campus de Jataí (GO), em um Latossolo Vermelho distroférrico, com relevo levemente ondulado, localizado a $17^{\circ} 53^{\prime}$ $\mathrm{S}$ e $51^{\circ} 43^{\prime} \mathrm{W}$, com altitude de $700 \mathrm{~m}$. O clima da região, segundo a classificação de Koppen, é do tipo $\mathrm{Cw}$, mesotérmico, com estações seca e chuvosa definidas. As médias mensais de temperatura e pricipitação estão apresentadas na figura 1. A área experimental foi cultivada anteriormente com a cultura da soja, em sistema de plantio direto e as características químicas e físicas eram: $\mathrm{pH}$ em água: 5,6; H+Al: $31 \mathrm{mmol}_{\mathrm{c}} \mathrm{dm}^{-3}$; Ca: $8 \mathrm{mmol}_{\mathrm{c}} \mathrm{dm}^{-3}$; Mg: 6 $\mathrm{mmol}_{\mathrm{C}} \mathrm{dm}^{-3} ; \mathrm{K}: 1,3 \mathrm{mmol}_{\mathrm{c}} \mathrm{dm}^{-3}$; SB: 15,3 $\mathrm{mmol}_{\mathrm{c}} \mathrm{dm}^{-3}$; CTC: $46,3 \mathrm{mmol}_{\mathrm{C}} \mathrm{dm}^{-3}$; V\%: 33; P: $3,5 \mathrm{mg} \mathrm{dm}^{-3}$; Areia: $437 \mathrm{~g} \mathrm{~kg}^{-1}$; Silte: $230 \mathrm{~g} \mathrm{~kg}^{-1}$ e Argila: $333 \mathrm{~g} \mathrm{~kg}^{-1}$.

Foram avaliadas nove espécies vegetais de cobertura: aveia-preta (Avena strigosa Schieb), guandu [Cajanus cajan (L.) Millsp.], Crotalaria juncea (Crotalaria juncea Roth), lablabe (Lablab purpureum L. Sweet), milheto (Pennicetum americanum L.), nabo forrageiro (Raphanus sativus L.), níger [Guizotia abyssinica (L.F.)], feijão-de-porco (Canavalia ensiformis L.) e Crotalatia spectabilis (Crotalatia spectabilis Roth), além de uma área em pousio, com vegetação espontânea, considerada como referência.

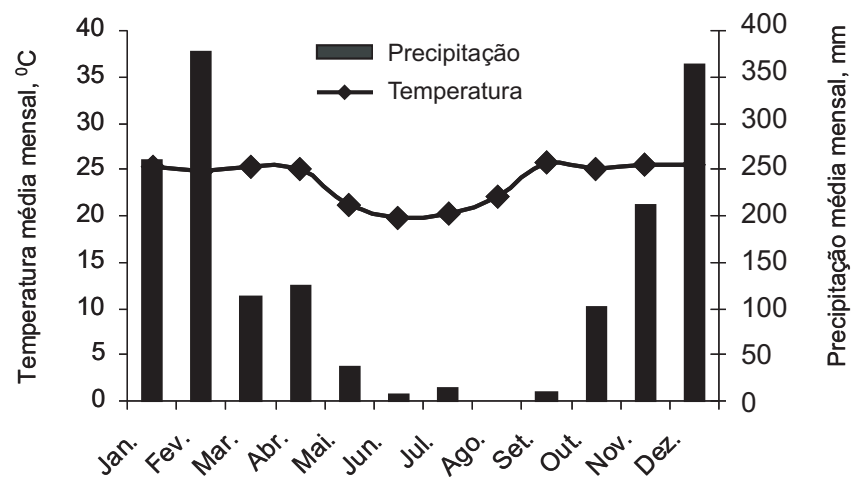

Figura 1. Médias mensais de temperatura $\left({ }^{0} \mathrm{C}\right)$ e precipitação (mm) no ano de 2004 em Jataí, GO. Informações obtidas da estação meteorológica da UFG/ CAJ-CCAB.

A semeadura das espécies de cobertura foi realizada em 27 de março de 2004, em delineamento experimental de blocos inteiramente casualizados, com cinco repetições. A unidade experimental foi constituída de parcelas com dimensões de $5 \mathrm{~m} \times 5 \mathrm{~m}$, perfazendo-se uma área de $25 \mathrm{~m}^{2}$ por parcela. A semeadura foi realizada nos sulcos com espaçamento característico para cada espécie vegetal. A adubação utilizada foi de $300 \mathrm{~kg} \mathrm{ha}^{-1}$ da fórmula 02-20-20 (NPK).

$\mathrm{Na}$ fase de florescimento foram coletadas as partes aéreas das espécies vegetais e na área em pousio, devido às diferentes épocas de florescimento e à diversidade de espécies, a coleta foi realizada aos 121 dias após o início do experimento. Nessa época, com auxílio de quadrado de madeira de $0,25 \mathrm{~m}^{2}$ foi coletada toda a fitomassa contida nesta área. $\mathrm{O}$ material fresco foi colocado em estufa de circulação de ar forçado, a $70^{\circ} \mathrm{C}$, até massa constante, determinando-se a quantidade de fitomassa e transformando-se os valores em toneladas por hectare. Na fitomassa foram determinadas as concentrações de nitrogênio pelo método micro Kjedahl, conforme SILVA E QueIrOZ (2002) e de carbono pelo método volumétrico do dicromato de potássio (EMBRAPA, 1999).

Na profundidade de $0-10 \mathrm{~cm}$ foi determinado o carbono orgânico do solo - Corg, em duas amostragens, sendo uma no início do experimento, em março, e outra no término, em dezembro, utilizandose o princípio volumétrico pelo dicromato de potássio e titulação com solução de sulfato ferroso amoniacal a 0,05 M (EMBRAPA, 1999). 
Após a última coleta de solo, em agosto de 2004, todas as plantas nas parcelas foram roçadas de tal maneira que o material remanescente na superfície do solo ficasse em fragmentos em torno de $4 \mathrm{~cm}$, espalhados homogeneamente por toda a área da parcela. Para determinar a razão de decomposição, foram utilizados $10 \mathrm{~g}$ da fitomassa coletada na época do florescimento, que foram acondicionados em sacos de polietileno "litter bag", com malha de $2 \mathrm{~mm}$, sendo retornados à parcela de origem, ficando por um período de 120 dias, até dezembro de 2004. No fim desse período, os sacos foram recolhidos e levados ao laboratório, onde a palha remanescente foi seca em estufa a $70{ }^{\circ} \mathrm{C}$, até massa constante e posteriormente pesada. Com os resultados, determinou-se a constante de decomposição $\mathrm{K}$, obtida pela equação de primeira ordem: $A_{t}=A_{0} e^{-k t}$, em que $A_{t}$ é a concentração do substrato remanescente em qualquer tempo $t$, e o cálculo da meia vida $\left(\mathrm{t}_{1 / 2}\right)$ da palhada, pela seguinte equação: $\ln \left[\left(\mathrm{A}_{0} / 2\right) / \mathrm{A}_{0}\right]=-\mathrm{Kt}_{1 / 2}$, em que $\mathrm{t}_{1 / 2}=0,693 /$ K (Paul e Clark, 1989).

As avaliações da atividade microbiana respiração microbiana e do carbono da biomassa microbiana - BM-C, foram realizadas no solo, em cada parcela durante o período de agosto a dezembro de 2004. Foram retiradas amostras de solo na profundidade de $0-10 \mathrm{~cm}$, no inicio de cada mês, com exceção de novembro, quando se coletaram amostras a cada 15 dias. Para determinação do carbono da biomassa microbiana - BM-C, foi utilizada a metodologia da fumigação-extração, proposta por VANCE et al. (1987). A BM-C foi obtida pela diferença entre as amostras fumigadas e não fumigadas, utilizando-se fator de correção de 0,30. A atividade microbiana do solo, determinada pela respiração microbiana, foi estabelecida em função da evolução de $\mathrm{CO}_{2}$ capturado pelo $\mathrm{NaOH}$, a partir de amostra de solo incubado por 72 horas, em ambiente hermeticamente fechado (AlEF E NANNIPIERI, 1995). O quociente metabólico - $q \mathrm{CO}_{2}$ foi obtido na relação entre a respiração e o carbono da biomassa microbiana (ANDERSOn e Domsch, 1993). O quociente microbiano foi obtido na relação entre o carbono da biomassa microbiana - BM-C e o carbono orgânico do solo Corg (BROOKES, 1995).

Os resultados foram submetidos à análise de variância pelo teste $\mathrm{F}$ e as médias pelo teste de Tukey a $5 \%$ de probabilidade de erro.

\section{RESULTADOS E DISCUSSÃO}

Os rendimentos de fitomassa das espécies de cobertura do solo foram diferentes entre si (Tabela 1). Verificaram-se valores significativamente superiores em feijão-de-porco, guandu, milheto e niger. Nas espécies Crotalaria juncea, Crotalatia spectabilis, lablabe e aveia preta obtiveram-se menores valores de fitomassa sendo, no entanto, superiores ao da área em pousio, com vegetação espontânea. Observou-se a presença, em maior densidade populacional, do picão preto (Bidens pilosa L.), capim amargoso [Digitaria insularis (L.) Mea ex Ekmon] e guanxuma-branca (Sida glaziovii K. Schum.), o que mostra a importância da utilização de espécies de cobertura do solo no período da entressafra, no outono-inverno.

Tabela 1. Rendimento de fitomassa, concentração de carbono e nitrogênio na fitomassa, relação $\mathrm{C} / \mathrm{N}$, constante de decomposição $(\mathrm{K})$ e meia vida $\left(\mathrm{t}_{1 / 2}\right)$ de resíduos das espécies vegetais de cobertura do solo. Jataí, (GO), outonoinverno de 2004

\begin{tabular}{|c|c|c|c|c|c|c|c|c|c|}
\hline \multirow{2}{*}{ Espécie } & \multirow{2}{*}{ DAF } & \multicolumn{3}{|c|}{ Fitomassa } & \multirow{2}{*}{$\mathrm{C}$} & \multirow{2}{*}{$\mathrm{N}$} & \multirow{2}{*}{$\mathrm{C} / \mathrm{N}$} & \multirow{2}{*}{$\mathrm{K}$} & \multirow{2}{*}{$t_{1 / 2}$} \\
\hline & & Produção & Folhas $\left({ }^{2}\right)$ & $\operatorname{Ramos}\left({ }^{2}\right)$ & & & & & \\
\hline & & $\mathrm{Mg} \mathrm{ha}^{-1}$ & 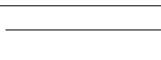 & $\%$ & & $\bar{z}$ & & & \\
\hline Aveia preta & 70 & $6,27 \mathrm{bc}$ & 79 & 21 & 58,99 & 1,83 & 32 & $0,011 \mathrm{a}$ & $72 \mathrm{a}$ \\
\hline Crotalaria juncea & 62 & $7,96 \mathrm{bc}$ & 30 & 70 & 49,51 & 3,01 & 16 & $0,011 \mathrm{a}$ & $71 \mathrm{a}$ \\
\hline Crotalaria espectabilis & 86 & $9,13 \mathrm{bc}$ & 42 & 58 & 49,97 & 2,17 & 23 & $0,011 \mathrm{a}$ & $66 \mathrm{a}$ \\
\hline Feijão-de-porco & 121 & $14,69 \mathrm{a}$ & 87 & 13 & 51,01 & 3,45 & 15 & $0,010 \mathrm{a}$ & $61 \mathrm{a}$ \\
\hline Guandu & 121 & $16,93 \mathrm{a}$ & 80 & 20 & 55,3 & 2,61 & 21 & $0,010 \mathrm{a}$ & $77 \mathrm{a}$ \\
\hline Lablabe & 86 & $8,66 \mathrm{~b}$ & 32 & 68 & 52,43 & 5,01 & 10 & $0,011 \mathrm{a}$ & $64 a$ \\
\hline Milheto & 53 & 16,39 a & 38 & 62 & 54,2 & 1,42 & 38 & $0,009 a$ & $60 \mathrm{a}$ \\
\hline Nabo forrageiro & 53 & $5,29 \mathrm{~cd}$ & 19 & 83 & 44,5 & 4,01 & 11 & $0,010 \mathrm{a}$ & $63 a$ \\
\hline Níger & 70 & $14,02 \mathrm{a}$ & 42 & 58 & nd & nd & $\mathrm{Nd}$ & $0,011 \mathrm{a}$ & $65 \mathrm{a}$ \\
\hline Vegetação espontânea & 121 & $3,06 \mathrm{~d}$ & 42 & 58 & nd & $\mathrm{Nd}$ & $\mathrm{Nd}$ & $0,011 \mathrm{a}$ & $70 \mathrm{a}$ \\
\hline
\end{tabular}

DAF: Dias até o florescimento. $\left({ }^{2}\right)$ Porcentagem em relação à produção de fitomassa. nd - não determinado. Médias seguidas pela mesma letra, na coluna, não são diferentes entre si, pelo teste de Tukey a $5 \%$ de probabilidade. 
Em relação à área em pousio, naquelas com guandu e milheto a produtividade de fitomassa foi em torno de 4,5 vezes superior, contribuindo para maior proteção do solo, além da provável não propagação de espécies de plantas não desejáveis. No nabo forrageiro constatou-se pequena produção de fitomassa, o que pode ser devido a sua menor adaptação para a região de cerrado em Goiás.

Os resultados deste estudo para o milheto, guandu e feijão-de-porco foram superiores quando comparados aos de outros estudos. Oliveira (1994) verificou uma produção de fitomassa do milheto e do feijão-de-porco de 14,2 e 3,43 $\mathrm{Mg} \mathrm{ha}^{-1}$ respectivamente, valores para o milheto próximos aos deste estudo e muito discrepante com relação aos do feijão-de-porco. Em estudo de De-Polli e ChADA (1989) foi obtido, para o milheto, somente a metade da fitomassa produzida neste estudo. PERIN et al. (2004) constataram valores de 9,3 Mg ha ${ }^{-1}$ para crotalária e de 7,12 $\mathrm{Mg} \mathrm{ha}^{-1}$ para milheto. Os valores de quantidades de fitomassa do nabo forrageiro e da aveia foram semelhantes aos de outros estudos desenvolvidos com essas espécies de cobertura, sendo variáveis de 4 a $8 \mathrm{Mg} \mathrm{ha}^{-1}$ para a aveia e de 2 a $6 \mathrm{Mg} \mathrm{ha}^{-1}$ para o nabo forrageiro (BORKert et al., 2003; Crusciol et al., 2005).

A maior produção de fitomassa verificada nesse estudo deve-se, provavelmente à época de semeadura e à adubação utilizada, com as quais houve condições adequadas para o desenvolvimento das espécies, pois na região constataram-se elevados índices de precipitação pluvial no início do desenvolvimento vegetativo (Figura 1). Na prática, quando o agricultor utiliza alguma espécie de cobertura no período de outono-inverno não realiza qualquer tipo de adubação, sendo aproveitada a adubação residual da cultura anteriormente cultivada.

A produção de fitomassa é um requisito importante para a adoção de uma espécie em sistemas de produção conservacionistas, quando se utiliza a palha para proteção do solo no período de outonoinverno, como no caso do sistema de plantio direto, além da diversificação da sucessão soja /milho, característica na região de cerrado. Segundo Darolt (1998), a quantidade mínima de fitomassa requerida para um eficiente sistema de rotação está em torno de $6 \mathrm{Mg}_{\text {ha }}{ }^{-1}$ em sistema de plantio direto, valor constatado em todas as plantas de cobertura do solo avaliadas neste estudo, com exceção da vegetação espontânea na área sob pousio, indicando que, com a escolha de uma estratégia de manejo, pode-se proteger o solo. A definição de espécies produtoras de fitomassa tem merecido alguns estudos, nos quais se determinaram espécies com potencial para utilização em solos de cerrado (SODRÉ FILHO et al., 2004; AMABILE et al., 2000).
Apesar das espécies de cobertura da família das leguminosas terem elevada concentração de nitrogênio, portanto menor relação $\mathrm{C} / \mathrm{N}$ - ao redor de 15 , no caso do guandu e do feijão-de-porco, elevada porcentagem de folhas na fitomassa (Tabela 1), condicionante de mais rapidez na decomposição, não se verificaram diferenças significativas entre as constantes de decomposição $\mathrm{K}$ e a meia vida da fitomassa $t_{1 / 2}$. Foram necessários, em média, 67 dias para a decomposição de metade da quantidade da fitomassa, independentemente das espécies de cobertura estudadas (Tabela 1). Esse processo se deve, principalmente, às condições climáticas características da região, tais como elevadas temperaturas e precipitações pluviais (Figura 1), que favoreceram aumento na razão de decomposição, independentemente da espécie de cobertura do solo. Além disso, deve-se considerar que, com as espécies da família das leguminosas, pode ter sido promovida a introdução de nitrogênio, via fixação biológica, interessante para a melhoria química do solo. Considerando-se a quantidade de fitomassa do guandu e do feijão-de-porco, pode-se aventar uma introdução no solo de 442 e $507 \mathrm{~kg} \mathrm{ha}^{-1}$ de N, respectivamente, enquanto, com o milheto, somente de $233 \mathrm{~kg} \mathrm{ha}^{-1}$ de $\mathrm{N}$. Portanto, com a utilização de leguminosas promovese melhoria na fertilidade do solo, principalmente quanto ao nitrogênio, nutriente mais exigido no desenvolvimento da maioria das plantas cultivadas.

O carbono da biomassa microbiana (BM-C) foi variável em função das espécies de cobertura do solo (Figura 2). Em agosto, setembro, segunda quinzena de novembro e dezembro, não se observaram diferenças significativas entre as espécies de cobertura do solo. A restrição hídrica em agosto e setembro, aliada à redução da temperatura (Figura 1), provavelmente, foram limitantes ao aumento da BM-C. Em novembro e dezembro, a não-diferença entre as espécies devese possivelmente à diminuição da fração facilmente decomponível da fitomassa de cada espécie, visto que foram constatados aumentos da BM-C em outubro e na primeira quinzena de novembro.

Com as espécies nabo forrageiro, milheto e crotalária espectábilis não foram promovidos incrementos na BM-C em relação à vegetação espontânea no pousio, com diferenças significativas das demais espécies estudadas em outubro; no entanto, com as espécies feijão-de-porco, crotalária júncea, níger e aveia foram proporcionados aumentos de $190 \%, 125 \%, 107 \%$ e $93 \%$ respectivamente, em relação à área em pousio. Esse aumento deve-se à qualidade bromatológica das fitomassas, nas quais a relação $\mathrm{C} / \mathrm{N}$ foi menor e maior quantidade de folhas em relação à de ramos, material mais lignificado (Tabela 1), associado ao início do período chuvoso, com exceção da aveia (C/N: 32) e do níger (nd). 


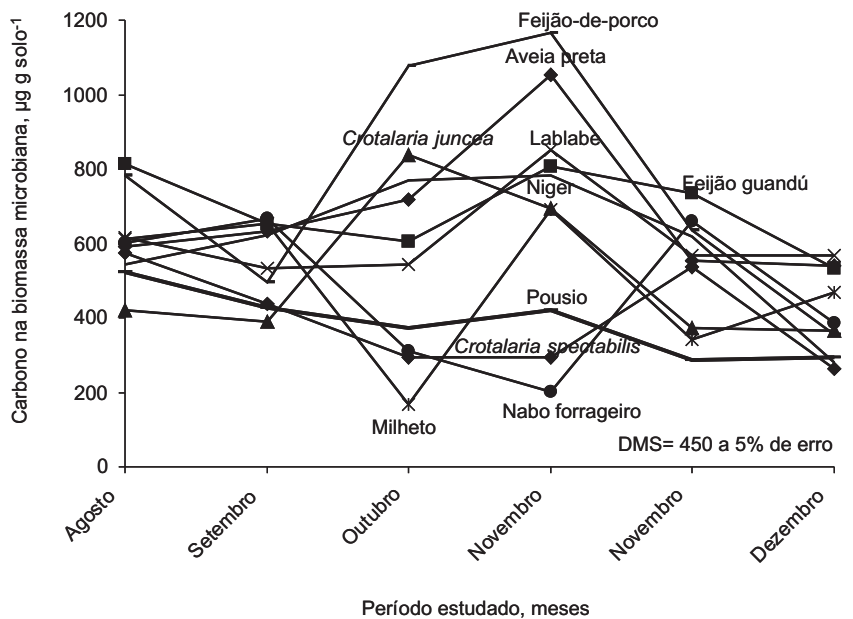

Figura 2. Teores de carbono da biomassa microbiana em função dos resíduos das diversas espécies de cobertura do solo em Jataí (GO), 2004.

$\mathrm{Na}$ primeira quinzena de novembro, constatou-se o mesmo comportamento do ocorrido em outubro, com exceção da área com resíduo de milheto em que, nesta época, obteve-se aumento da BM-C; pela maior relação $C / N$ pode ser induzida deficiência de $\mathrm{N}$ na cultura subseqüente caso medidas corretivas não sejam adotadas.

A biomassa microbiana é considerada catalizadora do solo, tendo grande importância no processo da decomposição dos resíduos orgânicos e na ciclagem de nutrientes (Moreira e Siqueira, 2002). Assim, aumentos na biomassa microbiana são condicionantes de um incremento na ciclagem de nutrientes no solo, pois estão imobilizados na fitomassa; após a decomposição, são liberados para o solo e a própria biomassa microbiana constitui-se em uma reserva lábil de nutrientes, também rapidamente liberados para o solo, em virtude do baixo tempo de vida dos microrganismos. Nas áreas cujos resíduos proporcionaram aumento na BM-C, ocorreu maior mineralização dos nutrientes imobilizados na fitomassa, em relação às áreas com menor BM-C, promovendo-se o enriquecimento do solo.

Não se constataram diferenças $(\mathrm{P}<0,05)$ para a atividade microbiana e o carbono orgânico do solo entre as espécies de cobertura e a época de amostragem. Para a determinação dos quocientes metabólico $\left(q \mathrm{CO}_{2}\right)$ e microbiano (BM-C/ Corg) foram utilizados dados obtidos para a BM-C, em outubro e na primeira quinzena de novembro, época em que houve diferenças significativas entre as espécies de cobertura com relação a BM-C. $\mathrm{O} q \mathrm{CO}_{2}$ foi superior em áreas sob resíduos de milheto, nabo forrageiro, crotalária espectábilis e, na área sob pousio, em outubro e novembro (Tabela 2). Esse fato revela que nessas áreas está ocorrendo perda de carbono na forma de $\mathrm{CO}_{2}$ para a atmosfera, ou seja, com os resíduos dessas espécies de cobertura pode ter havido um estresse na população microbiana que consumiu mais energia, na forma de carbono, para manutenção da mesma biomassa microbiana. Nas áreas sob resíduos de crotalária júncea, aveia e guandu constataram-se os menores valores de $q \mathrm{CO}_{2}$, demonstrando o efeito positivo dos resíduos dessas coberturas na população microbiana do solo.

Verificou-se a mesma tendência do $q \mathrm{CO}_{2}$ para o quociente microbiano, ou seja, pequenos valores nas áreas sob milheto, nabo forrageiro, crotalária espectábilis e em pousio (Tabela 2). Segundo ANDERSON e Domsch (1989), valores para áreas em rotação de culturas situam-se em torno de 4,0. Acima ou abaixo deste valor corresponde acúmulo ou perda de carbono do sistema, respectivamente; assim, verificam-se acúmulo e perdas com as espécies estudadas, indicativo da importância da escolha da cobertura para a melhoria da qualidade do solo.

Neste estudo, nas áreas sob resíduos de milheto, nabo forrageiro, crotalária espectábilis e em pousio, foi promovida a redução de carbono no solo, comprovada pelo elevado $q \mathrm{CO}_{2}$ e pequena relação BM-C/Corg. Associado a isso, tem-se menor quantidade de fitomassa produzida pelo nabo forrageiro, crotalária espetábilis e na área em pousio, proporcionando-se menos proteção do solo, prejuízos na atividade microbiana do solo e menos ciclagem de nutrientes. Se for considerada a quantidade imobilizada de nitrogênio na fitomassa e, já que em todas as espécies estudadas não houve diferenças $(\mathrm{P}<0,05)$ na razão de decomposição, após a completa decomposição/ mineralização seriam liberados 507 e $356 \mathrm{~kg} \mathrm{ha}^{-1}$ de $\mathrm{N}$, respectivamente, pelas espécies como feijão-de-porco e guandu; na a área sob milheto, nabo forrageiro, crotalária espectábilis e aveia, os valores seriam 233, 212,198 e $115 \mathrm{~kg} \mathrm{ha}^{-1}$ de $\mathrm{N}$ respectivamente.

A determinação de espécies de cobertura produtoras de fitomassa e os efeitos dos resíduos no solo são importantes para a adoção de estratégias adequadas de manejo visando à sustentabilidade do solo. Com as espécies feijão-de-porco, crotalária júncea, níger e a aveia onde se produziram quantidades satisfatórias de fitomassa, são promovidos aumentos no carbono da biomassa microbiana, baixo $q \mathrm{CO}_{2}$ e incrementos no quociente microbiano. Com espécies como o milheto (apesar da elevada produtividade de fitomassa), nabo forrageiro e crotalária espectábilis foi observada redução no carbono da biomassa microbiana e no carbono orgânico do solo. Na área em pousio, foram verificados mais prejuízos para a sustentabilidade do solo, demonstrando o efeito negativo de se deixar o solo com vegetação espontânea infestante, prática comumente utilizada. 
Tabela 2. Respiração microbiana do solo $\left(\mathrm{C}-\mathrm{CO}_{2}\right)$, carbono orgânico do solo (Corg), quociente metabólico $(q \mathrm{CO} 2)$ e microbiano (Cmic/Corg) do solo sob resíduos de espécies de cobertura do solo. Jataí (GO), outono-inverno de 2004

\begin{tabular}{|c|c|c|c|c|c|c|c|}
\hline \multirow{2}{*}{ Espécie } & \multicolumn{2}{|c|}{$\mathrm{C}-\mathrm{CO}_{2}$} & \multirow{2}{*}{$\frac{\text { Corg }}{\text { Dezembro }}$} & \multicolumn{2}{|c|}{$q \mathrm{CO}_{2}$} & \multicolumn{2}{|c|}{ BM-C / Corg } \\
\hline & Outubro & Novembro & & Outubro & Novembro & Outubro & Novembro \\
\hline & $\mu \mathrm{g} g$ & $1 \mathrm{o}^{-1} \mathrm{~h}^{-1}$ & $\mathrm{~g} \mathrm{~kg}^{-1}$ & $\mu \mathrm{g} \mathrm{C}-\mathrm{CO}_{2}$ & $\mu \mathrm{g} \mathrm{BM}-\mathrm{C}^{-1}$ & $\mu \mathrm{g}$ BM-C & $\mu \mathrm{g} \mathrm{Corg}^{-1}$ \\
\hline Aveia preta & $1,67 \mathrm{a}$ & $3,55 \mathrm{a}$ & $18,90 \mathrm{a}$ & 2,32 & 3,37 & 3,8 & 5,6 \\
\hline C. juncea & $2,13 \mathrm{a}$ & $2,95 \mathrm{a}$ & $18,76 \mathrm{a}$ & 2,55 & 4,25 & 4,5 & 3,7 \\
\hline Crotalaria espectábilis & $1,83 \mathrm{a}$ & $3,23 \mathrm{a}$ & $20,34 \mathrm{a}$ & 8,67 & 12,23 & 1,8 & 2,1 \\
\hline Feijão-de-porco & $1,76 \mathrm{a}$ & $1,64 \mathrm{a}$ & $18,67 \mathrm{a}$ & 1,63 & 1,41 & 5,7 & 6,2 \\
\hline Guandu & $2,76 \mathrm{a}$ & $2,52 \mathrm{a}$ & $19,47 \mathrm{a}$ & 4,58 & 3,12 & 3,1 & 4,1 \\
\hline Lablab & $2,61 \mathrm{a}$ & $2,75 \mathrm{a}$ & 18,99 a & 4,81 & 3,24 & 2,8 & 4,5 \\
\hline Milheto & $2,47 \mathrm{a}$ & 3,59 a & $19,56 \mathrm{a}$ & 14,87 & 5,21 & 0,8 & 3,5 \\
\hline Nabo forrageiro & $2,34 \mathrm{a}$ & $2,02 \mathrm{a}$ & $20,47 \mathrm{a}$ & 7,55 & 10,05 & 1,5 & 0,9 \\
\hline Niger & $3,33 \mathrm{a}$ & $4,57 \mathrm{a}$ & $17,75 \mathrm{a}$ & 4,34 & 5,85 & 4,3 & 4,4 \\
\hline Vegetação espontânea & $3,21 \mathrm{a}$ & 5,15 a & $20,21 \mathrm{a}$ & 6,22 & 10,95 & 1,4 & 1,5 \\
\hline
\end{tabular}

Médias seguidas pela mesma letra, na coluna, não são diferentes entre si pelo teste de Tukey a 5\% de significância.

\section{CONCLUSÕES}

1. O guandu, milheto, feijão-de-porco e níger são espécies adequadas à obtenção de rendimentos de fitomassa, superiores a $14 \mathrm{t} \mathrm{ha}^{-1}$ no outono-inverno.

2. Com a palha de feijão-de-porco, aveia, lablabe, crotalaria juncea e níger tem-se um incremento no carbono da biomassa microbiana do solo no início das chuvas.

3. A prática do pousio com vegetação espontânea infestante deve ser evitada para redução dos prejuízos no carbono da biomassa microbiana e no carbono orgânico do solo.

\section{AGRADECIMENTOS}

À Superintendência Municipal de Ciência e Tecnologia, de Jataí, e ao CNPq pelas concessões de bolsas de iniciação científica.

\section{REFERÊNCIAS}

ALEF, K.; NANNIPIERI, P. Methods in applied soil microbiology and biochemistry. London: Academic Press, 1995. 576p.

AMABILE, R.F.; FANCELLI, A.L.; CARVALHO, A.M. Comportamento de espécies de adubos verdes em diferentes épocas de semeadura e espaçamentos na região dos cerrados. Pesquisa Agropecuária Brasileira, Brasília, v. 35, n. 1, p. 47-54, 2000.

ANDERSON, J.P.E.; DOMSCH, K.H. Ratios of microbial biomass carbon to total organic carbon in arable soils. Soil Biology and Biochemistry, Oxford, v. 21, n. 4, p. 471-479, 1989.
ANDERSON, J.P.E.; DOMSCH, K.H. The metabolic quotient $(q \mathrm{CO} 2)$ as specific activity parameters to asses the effects of environment conditions, such as $\mathrm{pH}$, on microbial biomass of forest soils. Soil Biology and Biochemistry, Oxford, v. 25, n. 3, p. 393-395, 1993.

ASSIS, E.P.M.; CORDEIRO, M.A.S.; PAULINO, H.B.; CARNEIRO, M.A.C. Efeito da aplicação de nitrogênio na atividade microbiana e na decomposição da palhada de sorgo em solo de cerrado sob plantio direto. Pesquisa Agropecuária Tropical, Goiânia, v. 33, n. 2, p. 107-112, 2003.

BORKERT, C.M.; GAUDÊNCIO, C.A.; PEREIRA, J.E.; PEREIRA, L.R.; OLIVEIRA JÚNIOR, A. Nutrientes minerais na biomassa da parte aérea em culturas de cobertura de solo. Pesquisa Agropecuária Brasileira, Brasília, v. 38, n. 1, p. 143-153, 2003.

BRAGAGNOLO, N.; MIELNICZUK, J. Cobertura do solo por resíduos de oito seqüências de culturas e seu relacionamento com a temperatura e umidade do solo, germinação e crescimento inicial do milho. Revista Brasileira de Ciência do Solo, Campinas, v.14, n. 1, p.91-98, 1990.

BROOKES, P.C. The use of microbial parameters in monitoring soil pollution by heavy metals. Biology and Fertility of Soils, Berlin, v. 19, n. 2/3, p. 269-279, 1995.

COLOZZIFILHO, A.; ANDRADE, D.S; BOLOTA, E.L. Atividade microbiana em solos cultivados em sistema de plantio direto. Informe Agropecuário, Belo Horizonte, v. 22, n. 208, p. 84-91, 2001.

CRUSCIOL, C.A.C.; COTTICA, R.L.; LIMA, E.V.; ANDREOTTI, M.; MORO, E.; MARCON, E. Persistência de palhada e liberação de nutrientes do nabo forrageiro no plantio direto. Pesquisa Agropecuária Brasileira, Brasília, v. 40, n.2, p. 161-168, 2005.

DAROLT, M.R. Princípios para implantação e manutenção do sistema. In: DAROLT, M.R. Plantio direto: pequena propriedade sustentável. Londrina: IAPAR, 1998. p. 16-45. 
DE-POLLI, H.; CHADA, S. S. Adubação verde incorporada ou em cobertura na produção de milho em solo de baixo potencial de produtividade. Revista Brasileira de Ciência do Solo, Campinas, v.13, n. 2, p.287-293, 1989.

EMBRAPA. Manual de análises químicas de solos, plantas e fertilizantes. Brasília: Embrapa CNPS, 1999. 370 p.

FIALHO, J. F.; BORGES, A. C.; BARROS, N. F. Cobertura vegetal e as características químicas e físicas e a atividade da microbiota de um latossolo vermelho-amarelo distrófico. Revista Brasileira de Ciência do Solo, Campinas, v.15, n. 1, p.21-28, 1991.

LAL, R. Modification of soil fertility characteristics by management of soil physical properties. In. LAL, R.; GREENLAND, D.I. (Eds) Soil physical properties and crop production in the tropics. New York: J. Wiley, 1979. p. 397-405.

MOREIRA, F.M.S.; SIQUEIRA, J.O. Microbiologia e Bioquímica do Solo. Lavras: Editora UFLA, 2002. 626p.

OLIVEIRA, E. L. Coberturas verdes de inverno e adubação nitrogenada em algodoeiro. Revista Brasileira de Ciência do Solo, Viçosa, v.18, n. 2, p.235-241, 2002.

PAUL, E.A.; CLARK, F.E. Soil microbiology and biochemistry. San Diego: Academic Press, 1989. 275 p.

PAULETTI, V.A. Importância da palhada e da atividade biológica na fertilidade do solo. In: CURSO SOBRE ASPECTOS BÁSICOS DE FERTILIDADE E MICROBIOLOGIA DO SOLO EM PLANTIO DIRETO, 3., 1999, Cruz Alta. Anais... Passo Fundo: Aldeia Norte, 1999. p. 56-66.

PERIN, A.; SANTOS, R.H.S.; URQUIAGA, S.; GUERRA, J.G.M.; CECON, P.R. Produção de fitomassa, acúmulo de nutrientes e fixação biológica de nitrogênio por adubos verdes em cultivo isolado e consorciado. Pesquisa Agropecuária Brasileira, Brasília, v. 39, n. 1, p. 35-40, 2004.
RICE, C. W.; MOORMAN T. B.; BEARE, M. Role of microbial biomass carbon and nitrogen in Soil Quality. In: DORAN, J. W.; JONES, A. J. (Ed.). Methods for assessing soil quality. Madison: Soil Science Society of America, 1996. p.203-216.

ROSOLEM, C.A.; CALONEGO, J.C.; FOLONI, J.S.S. Lixiviação de potássio da palhada de espécies de cobertura de acordo com a quantidade de chuva aplicada. Revista Brasileira de Ciência do Solo, Viçosa, v. 27, n. 2, p. 355-362, 2003.

SILVA, D.J.; QUEIROZ, A.C. Análise de alimentos: métodos químicos e biológicos. 3.ed. Viçosa: UFV, 2002. 235p.

SIQUEIRA, J.O.; MOREIRA, F.M.S.; GRISI, B.M.; HUNGRIA, M.; ARAUJO, R.S. Microrganismos e processos biológicos do solo: perspectiva ambiental. Brasília: Empresa Brasileira de Pesquisa Agropecuária, 1994. 142 p.

SODRÉ-FILHO, J.; CARDOSO, A.N.; CARMONA, R.; CARVALHO, A.M. Fitomassa e cobertura do solo de culturas de sucessão ao milho na região do cerrado. Pesquisa Agropecuária Brasileira, Brasília, v. 37, n. 8, p. 1079-1087, 2002.

VANCE, E.D.; BROOKES, P.C.; JENKINSON, D.S. An extraction method for measuring microbial biomass $C$. Soil Biology and Biochemistry, Amsterdam. v. 19, n. 6, p. 703-707, 1987.

WARDLE, D.A. A comparative assessment of factors with influence microbial biomass carbon and nitrogen levels in soil. Biological Reviews, United Kingdom. v. 67, n. 3, p. 321358, 1992. 